\title{
The Impact of Organizational Climate on the Performance of Human Resources (A field study on the employees working at the Aqaba Company for Managing and Operating ports)
}

\author{
Dr. Ali Atallah Salah \\ Dr. Manal Abdulrahman Al-Attili
}

Al Hussein Bin Talal University

\begin{abstract}
This paper is organized to prove that there is an effect of organization climate of the performance of human resources in Aqaba company for Managing and Operating ports, Thus the main goal of the paper is to measure the effect of climate, through questionnaire sheet included two axis, first one has 6 levels, and the second is functionality. The method which is used in this paper to have Mean, Standard deviation effect rank, and Eta, then analysis by OLS to have R2, and then ANOVA analyses. All tests supported that the null hypothesis of an impact of climate and accepted the null hypotheses.
\end{abstract}

\section{Section one}

\section{Introduction:}

\section{1-1: Preface:}

The modern business environment imposes many challenges, especially with the dominance of the liberal model of competition, whereas the enormous challenges that cast a shadow on the performance of the organizations, their abilities to compete, and their efforts to grow and develop in order to survive in an ever-changing environment have resulted in opening up the global markets and abolishing tariff and non-tariff barriers in front of the flow of products across countries, in addition to the globalization of competition and liberalization of global transactions, and the dominance of regional and international economic blocs. This reality imposes the necessity to create modern strategies, methods and management practices in order to guide the organization's performance in a scientific way which achieves the ideal exploitation of their resources. The excellence management as a modern and advanced management philosophy may be considered as the ideal solution, and the effective practice through which business organizations can succeed and excel in their business and activities, and increase their ability to face and address the challenges that characterize the reality of their business in this era in where the consumer has a huge number of alternatives and options available before him. The excellence management as a modern management practice which the organizations must strive to reach in order to achieve a state of excellence, superiority, and expansion, which will lead to enhance its competitive abilities, obtain the targeted market share, and continue in strength and building (Al-Hilalat, 2014).

Human resources are considered as the basic wealth of any organization (both productive and service organizations). Therefore, organizations try to maximize the benefit obtained from their human resources by developing them, which ultimately reflects on the quality of individuals' performance to the best in order to achieve their personal goals and the goals of the organization (Al-Khalidi, 2010).

The word climate is a metaphor for the environment and geographical nature. When used in management, it is an expression of the workplace, the factors surrounding it, the method of dealing, and how the human forces there interact with each other. The organizational climate indicates the values, customs, traditions, social classes, and their influence on the administrative process and the behavior of the workers in the organization (Harvey, 1983).

The aspects of interest in the organizational climate appear through the relationship between the climate and other organizational variables, especially in the field of dealing between the individual and the organizational environment in general, which is defined by two main axes: the first axis is represented by the characteristics of the individual, which are largely related to the knowledge system, his experience, background, education, and culture. The second axis is the work internal environment which describes the distinguishing characteristics of the organization from other organizations, which differ from one organization to another according to the specific dimensions of the organizational environment. The most famous distinguishing characteristics are the organizational structure, communication system, work procedures systems, leadership style, the decision-making method, work nature and conditions, external work environment, and workgroup. As all these dimensions constitute a general framework within which they operate through all organizations and are subject to social, cultural, economic, political, technological and legal effects (Waal, 2007). 


\section{2 -1: The Study Problem:}

The investment in human resources is considered the most important type of investment and the most influential in upgrading the level of any community, and in order for the development process to be done in a way that helps to achieve its objectives, many elements must be present which support this, including the availability of the appropriate climate that helps the human resources do their part in terms of increasing the capacity, skills, and experience of the human resources, which will lead to further progress on the level of the institution as a whole.

The study problem stems from the researchers' sense of the importance of diagnosing the reality of the organizational climate and its impact on the performance of human resources (in a field study on the employees of the Aqaba Container Terminal (ACT). This study is believed to be the first according to the researchers.

Furthermore, it responds in a scientific and objective way too many of the local and regional cries that debated the administrative reform of our institutions. The problem of the study was represented in the following question: "What is the impact of the organizational climate on the performance of human resources (a field study on the employees of Aqaba Container Terminal Company (ACT)?

\section{3-1: Study hypotheses:}

The dimensions of the organizational climate will be measured by testing the following hypotheses:

The first hypothesis: There is a statistically significant relationship between the organizational structure of the Aqaba Container Company (ACT) and the performance of human resources.

The second hypothesis: There is a statistically significant relationship between the technology used in Aqaba Container Terminal Company (ACT) and the performance of human resources.

The third hypothesis: There is a statistically significant relationship between the nature of the work of the company and the performance of human resources.

The fourth hypothesis: There is a statistically significant relationship between communication in Aqaba Container Terminal Company (ACT) and the performance of human resources.

The fifth hypothesis: There is a statistically significant relationship between the extent of participation of the employees in the Aqaba Container Company and the performance of human resources.

\section{3-1: The importance of the study:}

1. Enriching the organizational climate. The two variables that constitute the core of this study are in fact the most important organizational concepts, namely the organizational climate and the performance of human resources, which constitute an important source for the survival of the institution.

2. This study adds something new to the organizational climate and scientific research through the results achieved.

3. It aims to draw the attention of the company's managers to employ the dimensions of the organizational climate and its impact on the performance of the human resources.

4. It helps decision-makers in addressing problems and offers a number of important recommendations and suggestions through the results of the study which will upgrade the level of the organizational climate in the company.

5. This study contributes to the diagnosis of negative trends in the decision-making processes.

\section{4-1: Objectives of the study:}

1. It aims to determine the impact of the organizational climate on the performance of employees.

2. Determine the impact of the organizational structure on the performance of human resources. Clarifying the concept of organizational climate, and how and what factors. The study divided into 5 sections. The first section is an introduction. The second section is a literature review, third included data, and methodology, the fourth section is empirical results, the fifth section is concluded remarks.

3. The influence it.

\section{5 -1: Related studies:}

- (Noora, Rafiee, et. al, 2015) Organizational Climate and Work Addiction in Shahid Sadoughi University of Medical Sciences, 2014: a Case Study. Electronic Physician 7(8): 1602-1608. The occupational nature of employees in headquarters units of the University requires them to deal with support issues. Thus, there is some pressure on these employees to complete their assignments on time so that employees in the line units can accurately and expeditiously perform their duties. As a result, work addiction behaviors are sometimes observed among the headquarters personnel. Considering the importance of work addiction and recognizing the factors that intensify it, this study investigated the relationship between organizational climate and the work addiction of headquarters personnel at the Shahid Sadoughi University of Medical Sciences. Methods This descriptive-analytic study was conducted using stratified random sampling of 151 University employees in 2014. The data collection tool was an organizational climate questionnaire, which was supplemented by the Work Addiction Risk Test (WART). 
The data were analyzed using the Pearson test, Spearman test, independent t-test, Mann-Whitney test, one-way analysis of variance (ANOVA), and the Kruskal-Wallis test using IBM-SPSS version 20. Results The findings of this study showed that the organizational climate was at a moderate level, and employees were in the danger level in terms of work addiction. In addition, among the dimensions of organizational climate, the risk dimension had a significant relationship with work addiction $(\mathrm{p}<0.05)$, and the dimensions of structure and responsibility were significantly different from the occupational group and monthly salary $(\mathrm{p}<0.05)$. Single employees showed a significant difference from married employees in the two dimensions of criteria and conflict $(\mathrm{p}<0.05)$. Conclusion Since the organizational climate score was low and the work addiction score was at the high-risk level, this issue demands more attention of senior managers and human resource officers of organizations to improve the organizational climate and increase employees' awareness of work addiction.

\section{Section Two:}

\section{Literature review:}

\section{1 -2: Study background:}

The ability of the organization to contribute strategically to the excellence in its performance, solve its problems, and achieve its efficiency goals through strategic planning, so that it is distinguished from the rest of the organizations, and the departments that are keen to work and are proficient in accomplishing their tasks are the ones that are preserving their level of excellence in the labor market, in order to meet the requirements of the developed and renewable market and be distinguished in the labor market. Organizational excellence is the activities of the organization that strengthen the achievement through: the exploitation of opportunities, facing challenges in order to reach the highest levels, to ensure accomplishing the achievements constantly, having the courage to change, paying attention to quality over quantity, and to be always keen to perform tasks in a way that others do not expect (Alhilalat 2014).

In order to face the challenges and rapid changes in the business environment, this nature requires a new approach which responds and keeps pace with these challenges and changes. The organizational climate and its applications are among the most important challenges of the present century (The Digital Century). The business organizations strive to identify, capture, and use valuable information in processes that permit today's organizations to generate, distribute, and apply knowledge to help make rational management decisions, promote creativity, increase competitiveness, and the achievement of the strategic objectives of these organizations, increase their value, and improve their performance. Not all information is knowledge, and not all knowledge is valuable; that's why management should capture and use useful knowledge in the organization's activities and operations (Al-Faris, 2010).

The word "climate" is a metaphor for the environment and the nature of a geographical location that describes the seasons of the year and the atmospheric shifts that characterize that site from other sites. This term has been applied to the workplace considering that the organization is an organic organizational entity that interacts with the environmental factors surrounding it.

It affects them and gets affected by them on the one hand, and it is also a dynamic entity which human and non-human elements interact with one another, and are affected by each other (Al-Omyan, 2005: p. 305).

The organizational climate represents the internal work environment with its various variables, characteristics, and interactions. The organizational climate plays a major role in enhancing the ethical and functional behavior of the working individuals in terms of shaping, modifying, and changing values, customs, attitudes, and behavior.

Hence it can be said that the organizational structure represents the organization's character in all its dimensions. Its success in creating a suitable climate for the individuals will encourage the creation of a meaningful work environment that will instill stability and consistency for both the individuals and the organization. The individuals in the effective organizational environment will sense their importance in work, and their ability to participate in decision-making and contribute to policy-making and planning and a sense of trust will prevail between the management and the individuals (Hammoud, 2002: p.16).

\section{2 -2: The concept of excellence for the organizational climate:}

The performance of the efficient and distinguished workers in the organization whose performance in carrying out tasks and jobs assigned to them is characterized by seriousness, accuracy, and efficiency. The organization also depends on indicators and criteria in measuring the performance excellence, continuous attention to learning and training to develop professional abilities and capabilities, and to activate the employees' skills in creativity, innovation, and generation of ideas, and to realize the importance of the achievements of the employees, and their role in achieving the objectives of the organization, and good behavior with others (Daradka, 2010). 


\section{3 -2: Organizational excellence also begins when the organization considers the following:}

- The availability of the data of the vision and message within and outside the organization, which are adopted by senior management, and the availability of graphic design of the vision and message in an orderly manner, and with the broad participation of its employees.

- Defining the objectives of the organization: and the objectives of the interests, and the commitment to its content by everyone at all organizational and administrative levels, and the identification of concrete targeted outputs.

- Develop the strategy: which is characterized by realism and transparency to achieve the vision and mission of the organization, and achieve its objectives, and evaluate this strategy periodically and redraft if necessary.

- Continuous consultation and participation: of all workers in the organization in the strategic planning process, where it will be understood and known by all, and to take into account how the duties and functions of the workers in the organization are consistent with the strategic plan of the organization.

- Document review: which are the documents that support planning and are redrafted more frequently.

- Review and evaluation: through feedback from external and internal clients.

- The implementation of work plans and annual plans: through specific, clear and applicable time programs (B. Hirigappa, 2009).

\section{4-2: Culture dimensions of the organizational climate:}

The contemporary workers' organizations striving to achieve excellence, take into account the dimensions of organizational culture based on the following (Alwan, 2009):

First: The leadership dimension: It is considered as a support to the process of development and improvement, which is one of the most important requirements for building organizational culture. This dimension consists of the following:

1. The management awareness of the importance of employees.

2. The role of the management.

3. Accept responsibility for quality.

4. Comprehensive transformation of the organization's management.

5. Behavior and motivation.

6. Leading the change.

7. Participation, ownership, and risk.

Second: The dimension of the structures and systems: This dimension is considered one of the most important dimensions and aspects that describe the culture of the organization, because it related to the process of communication between employees at all the management and organizational levels, teamwork, tasks and training, education and consistency of the goal, and monitoring the progress in work. This demission consists of the following items (Wael, 2010):

1. Communication: This item measures a form of communication within the organization and its effectiveness, and communication efficiency. When management recognizes the importance of communication and calls for periodic meetings to present results and exchange information so that the communication channels remain open.

2. Teamwork: Whenever this concept prevails and is supported by the senior management and by the culture of the organization, the more it will lead to achieving the requirements of the application of the total quality management, which will lead to excellence.

3. Tasks: This item measures management's thinking and philosophy in terms of having common tasks and the extent to which all employees are informed.

4. Training: This item measures the style of the senior management of the organization in terms of being interested in training the employees as they are the most important resource in the organization.

5. Education: This item measures the extent of the organization's interest in education by encouraging employees to continue their education and develop their own skills and operations. The far-sighted organization is aware of the value of education for its employees.

6. The consistency of the goal: Which means the consistency of the goal, the total commitment of senior management and all levels of management of the organization in applying the philosophy of quality until it becomes part of its life and entity?

7. Progress monitoring: It regularly reviews the progress towards the quality culture of the organization, and communicates this to all employees of the organization.

Third: The dimension of client orientation: It focuses on the needs and desires of the client, both internal and external, and this is the responsibility of each individual within the organization. This dimension consists of the following items (Sharma, B. \& Gadenna, D., 2008): 
1. Internal clients 2. Suppliers. 3. Reverse feedback. 4. Solving common problems. 5. Participating in product planning. 6. Internal clients. 7. The management as a supplier and a client.

Fourth: The dimension of the process and measurement: This dimension is concerned with the processes that are carried out within the organization, and trying to carry out measurement processes and determine the standards and individuals for each process at all administrative levels of the organization. This dimension consists of the following items (Halalat, 2014):

1. Understanding the process, 2. Measurement. 3. Understanding the non-measurable aspects. 4. Understanding the differences. 5. Manipulating the system. 6. Inspection. 7. The damaged and the cost of quality.

Fifth: The dimension of continuous improvement: The process of improvement encompasses all aspects of the organization so that the work environment is favorable and encouraging to accommodate the modern management concepts of quality and excellence. This dimension consists of the following items (Curtal, 2011):

1. Planning. 2. Investment of ideas. 3. Using measurement. 4. Continuous improvement and review cycle. 5. Maximizing. 6. Quality certificates. 7. Profits.

\section{1-5 - 2: Organizational Structure:}

The organizational structure of the institution is similar to the skeleton of the human being. The health of the organizational structure of the institution is proof of the health of this institution and vice versa. The forms of organizational structures have multiplied and developed in an attempt to improve the performance, communication, and management process in all institutions, according to recent scientific studies and research.

The organizational structure determines how activities are directed, such as task mobilization, coordination, and supervision in order to achieve organizational objectives. The organization can be structured in many different ways, depending on its objectives. The structure of the organization identifies the ways in which it operates. This affects organizational work by providing the basic procedures for standard operation and defines the individuals' tasks in terms of participation, decision-making. There are many types of these structures which are used in companies, banks, and media organizations (Lim, M., 2017).

It usually consists of the activities and tasks that are distributed among the employees of the institution, and executing the processes of coordination and supervision, and are necessarily oriented towards the goals of the institution and the organization (Bohgh, DS, ed., 1990). It can also be seen as a mirror of the individuals towards their organization and the surrounding environment (Jacobides, MJ 2007). An organization or institution can be structured in many different ways according to its objectives. Therefore, the organizational structure determines its mode of operation and its results.

The organizational structure allows the identification of responsibilities for different functions and specific processes for different entities such as branches, departments, working groups, and individuals.

Institutional systems have two impacts on organizational work. First, it provides the foundation that controls standard operating procedures and routines. Second, it determines which individuals are responsible for decision-making in each procedure. Therefore, their views define the actions of the organization (Jacobides, M. 2007).

\section{2-5 -2 :Technology:}

Work Technology: We live in a world where technology has created a revolution that no one can deny. Technology has penetrated all walks life whether industrial, agricultural, commercial and educational. Today's world became different from the world of past years. As long as technology has entered and become part of all organizations, it is considered one of the elements of the organizational climate of these organizations, so these organizations should benefit from the advantages and improvements of technology, spread positive trends towards it, and invest it optimally.

Technology means bringing change and development to the organization, which helps to streamline work procedures and often gets rid of its routine aspects, and the muscle effort that it may require, and provide more opportunity for workers to exploit their potential capabilities and capacities, but on the other hand, the increased reliance on equipment and tools may make the organizational climate take a negative direction where it is characterized by immobility and inhumanity, and the human being in it becomes like the machine which moves in calculated steps and limited movements (Jacobides, MJ 2007).

Although contemporary technology is considered a blessing to human beings, it raises many concerns among workers particularly, and society at large. The use of advanced technology will increase the rate of unemployment in the society on the one hand, and reduce morale among workers on the other hand, where they will consider themselves merely a machine working on a machine (Almograbi, 1995: p. 305). 


\section{3-5-2: Communication:}

Communication plays an important role within organizations, and can be compared with blood that runs in human veins, and carries food to all parts of the body. For organizations, communication plays an important role in maintaining the influx and flow of work within organizations. The efficiency of work will increase whenever there are good communication systems, and the efficiency of managers is high at communications (Maher, 2005: p. 340).

Good communication is two-way communication because it gives employees opportunities to express an opinion, learn and develop (Al-Maghribi, 1995: p. 305). On the contrary, one-way communication (downward) that carries commands and instructions from the top down, and leads the individual to indifference and idle thinking, since his ideas and opinions are worthless to the managers (Al-Amyan, 2004: p. 308). The prevailing modes of communication will influence the creation of an organizational climate suitable for creativity, innovation, and contribution to decisionmaking. Communication is a social means through which individuals can understand each other, and create dynamic mobility (The Community and continuous interaction between the individual and the community). (Hamoud, 2002: p. 170). We believe that it is very necessary to have an effective communication system within the university in order to achieve a constructive communication within the university, between the staff and the administration, among the workers, between the different departments, deanships and colleges, and also outside the university with the external environment, where through effective communication the transfer and exchange of information and data is done quickly and easily within the university, and allows employees to express their opinions and ideas freely, which will make them since their value, which reflects on their performance positively.

The communication process is an indispensable necessity for all institutions in general, and for educational institutions in particular.

\section{4-5-2: Employee participation and performance:}

HR can have a major impact on a company by creating an in-depth awareness of the business among the employees, examining motivations behind employee behavior that moves the company's strategy forward, and forming a new basic qualification model for human resources professionals. The company's human resources department can also measure performance, but these measurements are unlikely to assess the real impact of this performance on final financial results.

Through this, we can understand the importance of evaluating the performance of employees as one of the dimensions of human resources development in the organization, by recognizing how useful they are to the organization in general and the workers in particular, as follows (Hanna, 2011):

- Enable the organization to assess supervisors and managers and their effectiveness in the advancement and development of team members under their supervision.

- Provide organizations with indicators of the performance, conditions, and problems of their workers.

- It is seen as a measure or criterion for business.

- Enable employees to know their weaknesses and strength in their work, and try to avoid and eliminate the shortcomings and weaknesses.

- A method followed by organizations to use objectivity and fairness in dealing with their employees by following realistic standards and specific measures.

- A method to detect weaknesses in systems, procedures, laws, working methods, adopted standards and their validity.

- Provides an opportunity for employees to correct their mistakes and work to avoid them, develop their skills, and achieve what they desire, such as promotions, getting rewards, and remunerative compensation.

- Helps to raise the morale of the workers and strengthen the ties and relations between the boss and the subordinate.

- It is useful in reducing the job turnover rate and the negativity in the behavior of workers, such as the absence, neglect, and lack of enthusiasm for work.

- Contributes to the detection of the untapped potentials of employees.

- Contributes to the adjustment of performance standards, and increase the performance of staff and the organization in general.

- Contributes to drawing up the organization's workforce plan, and what its requirements are, such as development, training, and provision of rewards and incentives for employees.

\section{5-5-2 : Leadership:}

Ability is to inspire others to make a voluntary and full commitment to or even exceed organizational goals. The impact of a successful leadership can be seen clearly in any organization with good leadership, who shares the following characteristics: 
positive behaviors, commitment to achieving organizational goals, high levels of production, High levels of quality, efficient and effective use of the organization's resources, and mutual support among working teams to accomplish work (Kdemir, Bunyamin, 2010).

\section{6-5-2: Principles of leadership:}

Due to the increasing competition in the business environment, the leadership has become of the personality traits and the managerial, technical and ethical capabilities of the employees. There are a number of principles on which the leadership relies on in achieving its objectives effectively. We mention the following (B. Hirigappa, 2009):

1. The leader shall make the right decisions at the right timing, solve the problems, make the decisions, and set the planned goals.

2. The leader knows the workers, works for them and understands human nature and the importance of caring for employees sincerely.

3. The leader seeks and bears responsibility, directs the organization to new visions, analyzes positions, corrects, and moves towards the new challenge.

4. The leader shall communicate the necessary information to the employees, and shall have excellent communication skills.

5. The leader shall be a role model and a distinctive example to the workers who will imitate him and consider him as a role model.

6. The leader develops a sense of responsibility in the workers and helps develop good characteristics that strengthen the workers' carrying out their professional responsibilities.

7. The leader is technically skilled, totally aware of his work field, and enjoys familiarity with the tasks that individuals perform in his surroundings.

8. The Leader shall employ all the human and material capacities of the organization to achieve the objectives.

9. The leader shall benefit from all the modern scientific and technological features and tools to achieve the objectives of the organization.

10. The leader knows himself and his positive characteristics, constantly looking for self-improvement, and constantly works to strengthen these characteristics. Among the distinctive characteristic of leadership are (Ugboro \& Obeng, 2000):

-Planning - Organization - Goal setting - Decision making - Risk - Communication skills - Change management Delegation. - Vision and creativity. - Stimulation. - Skills. - Commitment. - Flexibility and changeability. - Control of stress and work pressure- Team training, education, and building.

\section{Section Three:}

\section{Data and Methodology:}

The data were collected from Aqaba Company for Managing and Operating ports employments from different levels of managers and employees, including male and female,56 sheets, were 6 sheets are canceled with ratio $0.09 \%$ because they are not suitable for analysis, the method of analysis including Mean, Standard deviation ,effect rank, then Eta coefficients and OLS regression results of $\mathrm{R}^{2}$ to check the hypotheses of null hypotheses and finally ANOVA analyses to ensure of decisions of study hypotheses. The answers of the questionnaire are measured by strongly agree, agree, natural, strongly disagree, disagree, by Lieckert measurement method. The SPSS software utilized to analyze the data.

\section{Section four:}

\section{Empirical Results:}

The results of analyses stated in tables 1 to 7 which given the effect rank of each axis and each phrase to the answer of participants ,in table 1;0.09 of questionnaire answer were spoiled, thus 50 sheets are used in analyses, the demographic factors indicates to $70 \%$ of male and 30\% of female, most of the sample are youth with 55\% 40 years ago ,the educational levels are mostly BA, BCS degrees, higher diploma with 75\%, also service years as experience $40 \%$ of the above 11 years, managers, assistant managers are $30 \%$ of participants. 
Table (1): Distribution of Sample due to Demographic Status

\begin{tabular}{|c|c|c|c|}
\hline \multirow{3}{*}{ Gender } & & Frequency & Percentage ratio \\
\hline & Male & $70 \%$ & 35 \\
\hline & Female & $30 \%$ & 15 \\
\hline \multicolumn{2}{|c|}{ Total } & $100 \%$ & 50 \\
\hline \multirow{4}{*}{ Age } & $20-30$ & $20 \%$ & 10 \\
\hline & $31-40$ & $35 \%$ & 17 \\
\hline & $41-50$ & $20 \% 10$ & 10 \\
\hline & 51 Over & $25 \%$ & 13 \\
\hline \multicolumn{2}{|c|}{ Total } & $100 \%$ & 50 \\
\hline \multirow{4}{*}{ Education Levels } & Bachelor & $45 \%$ & \\
\hline & Higher diploma & $30 \%$ & \\
\hline & Master degree & $15 \%$ & \\
\hline & Ph.D. & $10 \%$ & \\
\hline \multicolumn{2}{|c|}{ Total } & $100 \%$ & \\
\hline \multirow{4}{*}{ Service } & 5 year & $25 \%$ & \\
\hline & $6-10$ years & $35 \%$ & \\
\hline & 11-1 years & $30 \%$ & \\
\hline & 16 more & $10 \%$ & \\
\hline \multicolumn{2}{|c|}{ Total } & $100 \%$ & \\
\hline \multirow{9}{*}{ Equitized } & Manager & $5 \%$ & \\
\hline & Vice Manager & $5 \%$ & \\
\hline & Head of Dept. & $10 \%$ & \\
\hline & Management Employed & $15 \%$ & \\
\hline & Technical Service & $15 \%$ & \\
\hline & Secretary & $10 \%$ & \\
\hline & Assistant Manager & $10 \%$ & \\
\hline & Labor & $20 \%$ & \\
\hline & Others & $10 \%$ & \\
\hline \multicolumn{2}{|c|}{ Total } & $100 \%$ & \\
\hline
\end{tabular}

In table (2) organizational structure phrases 1,2,4 are moderate, when 3,5 are highly hypotheses significant, were Eta is supported the effect ranked, and all phrases are highly effects. table (3) Technology phrases 1,2,4 phrases are moderates effects, were 3, and 5 are within high effects, Eta is significant . in table (4) work nature phrases 1,2,5 are moderate effects, were 3 and 4 phrases are within high effect, Eta test is significant, were null hypotheses rejected. The same results of table (5) communication phrases. In table (6) phrases 1,2, and 3 are a moderate effect, but 4 and 5 are high effect and null hypotheses rejected.

Table (2) The organizational structure results

\begin{tabular}{|l|l|c|c|c|l|l|}
\hline $\begin{array}{l}\text { Phrases } \\
\text { No }\end{array}$ & Mean & St/deviation & Effect level & Degree rank & ETA & Decision \\
\hline 1 & 3.801 & 0.8536 & Moderate & 5 & 0.763 & \\
\hline 2 & 3.765 & 0.7869 & Moderate & 3 & 0.845 & \\
\hline 3 & 3.816 & 0.7142 & High & 2 & 0.791 & \\
\hline 4 & 3.643 & 0.8392 & Moderate & 1 & 0.796 & \\
\hline 5 & 3.109 & 0.7091 & High & 4 & 0.812 & \\
\hline $\begin{array}{l}\text { All } \\
\text { phrases }\end{array}$ & 3.841 & 0.8677 & High & & & $\begin{array}{l}\text { Reject the } \\
\text { null } \\
\text { hypothesis }\end{array}$ \\
\hline
\end{tabular}


Table (3): Technology

\begin{tabular}{|l|l|c|c|c|l|l|}
\hline $\begin{array}{l}\text { Phrases } \\
\text { No }\end{array}$ & Mean & St/deviation & Effect level & Degree rank & ETA & Decision \\
\hline 1 & 3.801 & 0.8536 & Moderate & 5 & 0.763 & \\
\hline 2 & 3.765 & 0.7869 & Moderate & 3 & 0.845 & \\
\hline 3 & 3.816 & 0.7142 & High & 2 & 0.791 & \\
\hline 4 & 3.643 & 0.8392 & Moderate & 1 & 0.796 & \\
\hline 5 & 3.109 & 0.7091 & High & 4 & 0.812 & \\
\hline $\begin{array}{l}\text { All } \\
\text { phrases }\end{array}$ & 3.841 & 0.8677 & High & & & $\begin{array}{l}\text { Reject the } \\
\text { null } \\
\text { hypothesis }\end{array}$ \\
\hline
\end{tabular}

Table (4): Work Nature

\begin{tabular}{|l|c|c|c|c|c|c}
\hline $\begin{array}{l}\text { Phrases } \\
\text { No }\end{array}$ & Mean & St/deviation & Effect level & Degree rank & ETA & Decision \\
\hline 1 & 3.762 & 0.961 & Moderate & 4 & 0.657 & \\
\hline 2 & 3.539 & 0.975 & Moderate & 5 & 0.598 & \\
\hline 3 & 3.892 & 0.833 & High & 2 & 0.854 & \\
\hline 4 & 3.641 & 0.802 & High & 1 & 0.673 & \\
\hline 5 & 3.596 & 0.931 & Moderate & 3 & 0.879 & \\
\hline $\begin{array}{l}\text { All } \\
\text { phrases }\end{array}$ & & & High & & & $\begin{array}{l}\text { Reject null } \\
\text { hypothesis }\end{array}$ \\
\hline
\end{tabular}

\section{Table (5): Communication}

\begin{tabular}{|l|c|c|c|c|c|c}
\hline $\begin{array}{l}\text { Phrases } \\
\text { No }\end{array}$ & Mean & St/deviation & Effect level & Degree rank & ETA & Decision \\
\hline 1 & 0.3542 & 0.882 & Mode rate & 4 & 0.876 & \\
\hline 2 & 0.3987 & 0.896 & Mode rate & 5 & 0.923 & \\
\hline 3 & 0.3162 & 0.876 & Mode rate & 3 & 0.864 & \\
\hline 4 & 0.3669 & 0.716 & High & 1 & 0.781 & \\
\hline 5 & 0.3473 & 0.805 & High & 2 & 0.910 & \\
\hline $\begin{array}{l}\text { All } \\
\text { phrases }\end{array}$ & 3.634 & 0.820 & High & & & $\begin{array}{l}\text { Reject null } \\
\text { hypothesis }\end{array}$ \\
\hline
\end{tabular}


Table (6): The extent of staff participation

\begin{tabular}{|l|c|c|c|c|c|l}
\hline $\begin{array}{l}\text { Phrases } \\
\text { No }\end{array}$ & Mean & St/deviation & Effect level & Degree rank & ETA & Decision \\
\hline 1 & 0.9561 & 5 & Mode rate & 4 & 0.876 & \\
\hline 2 & 0.9332 & 4 & Mode rate & 5 & 0.923 & \\
\hline 3 & 0.8791 & 3 & Mode rate & 3 & 0.864 & \\
\hline 4 & 0.8635 & 2 & High & 1 & 0.781 & \\
\hline 5 & 0.8542 & 1 & High & 2 & 0.910 & \\
\hline $\begin{array}{l}\text { All } \\
\text { phrases }\end{array}$ & 3.6952 & 0.8679 & High & & & $\begin{array}{l}\text { Reject null } \\
\text { hypothesis }\end{array}$ \\
\hline
\end{tabular}

The second axis's is represents in table (7) represents the answer participants of questionnaire the functionality ( performance of employees);phrases 3,4,7,9 are highly effect and 1,2,5,6,8,10 are moderate performances, Eta supported these results. Results are stated in table (7).

Table (7) The functionality performance of employees

\begin{tabular}{|c|c|c|c|c|c|}
\hline No of phrase. & Mean & St/dev & Rank of effect & Effect level & Eta \\
\hline 1 & 3.9722 & 0.9786 & 9 & moderate & 0.754 \\
\hline 2 & 3.9150 & 0.9254 & 8 & moderate & 0.784 \\
\hline 3 & 3.9016 & 0.9682 & 7 & moderate & 0.823 \\
\hline 4 & 3.8167 & 0.7466 & 3 & High & 0.854 \\
\hline 5 & 3.7265 & 0.6935 & 1 & High & 0.917 \\
\hline 6 & 3.8019 & 0.9816 & 10 & moderate & 0.796 \\
\hline 7 & 3.8299 & 0.7024 & 2 & High & 0.938 \\
\hline 8 & 3.7615 & 0.8192 & 4 & moderate & 0.875 \\
\hline 9 & 3.0978 & 0.8554 & 5 & moderate & 0.794 \\
\hline 10 & 3.8752 & 0.8673 & 6 & High & 0.948 \\
\hline ALL & 3.9541 & 0.8598 & All & High & \\
\hline
\end{tabular}

The first hypotheses test indicates $\mathrm{R}^{2}=0.412$, T-test 16.52 and significant, reject null hypotheses.

Table (A): the test of first hypotheses

\begin{tabular}{|l|c|c|c|c|}
\hline Dependent & T.test & $\mathbf{R}$ & $\mathbf{R}^{\mathbf{2}}$ & Sig \\
\hline & 16.52 & 0.198 & 0.412 & 0.000 \\
\hline
\end{tabular}

As tests of second hypotheses result: $\mathrm{R} 2=\mathbf{0 . 4 4}$ and T-test is $\mathbf{1 2 . 7 5}$ resulted is significant, therefore null hypotheses are rejected.

Table (B): tests of second hypotheses

\begin{tabular}{|l|c|c|c|c|}
\hline Dependent & $\mathbf{R}^{2}$ & $\mathbf{R}$ & T-test & Sig \\
\hline & 0.44 & 0.21 & 12.75 & 0.004 \\
\hline
\end{tabular}

The $\mathrm{R}^{2}$ is 0.497 , T-test is 10.83 also it is significant, the null hypotheses are rejected

Table (C): The results of third hypotheses

\begin{tabular}{|l|c|c|c|c|}
\hline Dependent & $\mathbf{R}^{\mathbf{2}}$ & $\mathbf{R}$ & T-test & Sig \\
\hline & 0.497 & 0.231 & 10.83 & 0.007 \\
\hline
\end{tabular}


Table (D): The result of tests of fourth hypotheses

\begin{tabular}{|l|c|c|c|c|}
\hline Dependent & $\mathbf{R}^{\mathbf{2}}$ & $\mathbf{R}$ & T-test & Sig \\
\hline & 0.384 & 0.231195 & 10.83 & 0.000 \\
\hline
\end{tabular}

Also, fourth hypotheses are rejected due to results of T-test which is significant

Table (E): The results of fifth hypotheses

\begin{tabular}{|l|c|c|c|c|}
\hline Dependent & R2 & R & T-test & Sig \\
\hline & 0.505 & 0.225 & 14.39 & 0.004 \\
\hline
\end{tabular}

The T-test indicates that null hypotheses are rejected, were $\mathrm{R}^{2}=0.505$. The ANOVA analyses indicate that the null hypotheses are rejected.

Table (8): ANOVA analysis

\begin{tabular}{|c|c|c|c|c|c|}
\hline $\begin{array}{l}\text { Source of } \\
\text { Variance }\end{array}$ & $\begin{array}{l}\text { Sum } \\
\text { Squares }\end{array}$ & df & F Calc & F tab & Decision \\
\hline $\begin{array}{c}\text { Between } \\
\text { groups }\end{array}$ & & & 3 & 0.547 & \\
\hline $\begin{array}{c}\text { Within } \\
\text { groups }\end{array}$ & 3.92 & 6.398 & 200 & 19.720 & \\
\hline Total & & & 203 & 20.267 & $\begin{array}{l}\text { Reject null } \\
\text { hypothesis }\end{array}$ \\
\hline
\end{tabular}

\section{Section five:}

\section{Concluded remarks:}

The paper organized to prove characteristic of leadership in improving the climate in his establishment, the leader should be in positive characteristic, constantly looking for self-improvement and improvement of organization structure, mainly to achieve the goals, planning and organization, decision making, the vision of creativity, and another distinct characteristic of leadership. In this paper which organized in 5 sections, the goal of the paper gives the leader to seeks and bears the responsibility to improve the climate in his company. The questionnaire sheet included two axes, the first axis included 6 categories; organizational structure, work nature, technology, communication, the extent performance of employment. The phrases of the questionnaire sheet distributed to 56 people including male and female, tests indicate that null hypotheses are rejected, and alternative hypotheses, which proved that the climate is affected the process.

\section{References:}

Halalat, Saleh Ali Odeh. (2014). Management Excellence Modern practice in the management of business organizations. Dar Wael Publishing \& Distribution. First Printing, Amman, Jordan.

Daradka, Mamoun Mohammed and Shibli, Tarek Ahmed. (2010). Quality in modern organizations. Dar Safa for Publishing and Distribution. Ammaan Jordan.

Add to shortlist Alwan, Naif Kassem. (2009). Total Quality Management and ISO requirements. First Edition, Dar AlThaqafa for Publishing and Distribution, Jordan. Pp. 164-155.

Curtal, Fred. (2011). Quality and excellence in business organizations. First Arabic Edition, Arab Society Library for Publishing and Distribution, Amman, Jordan.

Pohang, d. S., Editor. (1990). Theories of Regulation: Selections for Reading. Harmondsworth: Penguin

Jacobites., M. C. (2007). The inherent boundaries of the organizational structure and the role of hierarchy failure: Lessons from an approximate war. Science Organization, 18, 3, 455-477.

Hamoud, Khudair Kazem. (2002). organizational behavior. Dar El Safaa For Publishing \& Distribution, Amman.

The Blind, Mahmoud Salman. Organizational Behavior in Business Organizations. Second edition, Dar Wael Publishing, 2005. Amman, Jordan. 
Hanna Nasrallah. (2001). Human Resource Management. Amman, Dar Zahran Publishing and Distribution, PO Box 1616-170.

B. Hirigappa. (2009). Organizational Behavior. New Age International Publishers. New Delhi. Pp. 198-199.

Kdemir, Bunyamin. (2010). Characteristic of the High-Performance Organization. The Journal of Faculty of Economics and Administrative Science. Vol. 15, No. 1, pp. 155-174.

Ugboro \& Obeng. (2000). Top Management Leadership. Satisfaction in Total Quality Management Organizations. Pp. $17-61$.

Weal, A. A. de. (2010). Achieving High Performance in the Public Sector, What needs to be Done? Int.www.hpo.center.com.

Sharma, B. \& Gadenna, D. (2008). An Empirical Investigation of the Relationship between Quality Management Factors and Customer Satisfaction, Improved Competitive Position and overall Business Performance. Journal of Strategy Marketing. Vol. (16). No. 14.

Harvey, L. J., "Effective Planning For Human Resource Development", Personnel Administration, (Vol. 28, No. 10, Oct. 1983), P.P.4-25.

Waal, A. A. de. (2007). The Characteristics of High-Performance Organizations Published in Business Strategy Sevice, Volume 8 Number 3. (Emerald, pp $179-185$.

Lim, M. (2017). Examining the literature on organizational structure and success. College Mirror, 43, 1, 1618. http://www.cfps.org.sg/publications/the-college-mirror/article/1098.

Noora, Rafiee \& Mohammad Amin Bahrami \& Vahid Zare \& Mahan Mohamadi. (2015). Organizational Climate and Work Addiction in Shahid Sadoughi University of Medical Sciences, 2014: a Case Study. Electronic Physician 7(8): 1602-1608

\section{One: The organizational climate:}

1- There are consistency and consistency of functions with the nature of the organizational structure

2 The organizational structure is characterized by good design and flexibility -

3- There is a degree of overlap and duplication in business and functions.

4- The division of labor in the company helps achieve its objectives.

5- The organizational structure of the company conforms to the nature and functions of the company, and leads to rapid completion of work and high quality.

\section{Second axis: Technology:}

1- The company is keen to keep abreast of technological developments and continuously develops them in order to increase performance.

2 - The technology used by the company has led to rapid work completion and improved service quality...

- The technology used by the company is easy to use and contributes to saving effort. 3

4- The company accomplishes most of its business using technology that complies with business requirements.

5 - There is a good knowledge of technological developments appropriate to the company's goals as a whole.

\section{Third: The nature of the work}

1 -Office designs provide psychological and physical comfort (ventilation, lighting, movement), and provide security and safety.

2 - Working hours and working hours are appropriate, as employees of the company enjoy the holidays they deserve according to the system.

Routine work overcomes my duties and my job duties. 3 -

4 - me work give us many opportunities for innovation and innovation.

5 - Work procedures related to my responsibilities are consistent with my abilities, skills, and qualifications.

\section{Fourth: Communication:}

-The company's communication system contributes to the company's goals. 1

2 - Administrative communication is easy and flexible and contacts between superiors and subordinates are very rapid.

3- The company will use all channels of communication in all directions (ascending - down - horizontal), striving to

overcome the obstacles.

4 - Superior administrative levels can be contacted without hindrance

5 -The company's communication system contributes to providing the necessary information for decision making. 


\section{Fifth: The extent of participation of workers:}

1 - Employees participate in setting the objectives of the business units and decision-making related to the work units.

2 - Decision-makers resort to consultations before making decisions to determine their results and effects

-Employees have the power and legal authority to make and take important decisions 3

. - Different alternatives are evaluated and available before decisions are made4

Workgroup problems are resolved collectively.

\section{Sixth: Leadership :}

-The leadership style of the company helps to advance and advance it 1

The direct administrator allows staff to participate in decision-making2 -

3-The direct supervisor works to motivate individuals and encourage them to change, innovate, and innovate

4-The Department provides the necessary support to carry out my work and the duties required of me

5-The direct supervisor encourages me to solve the business problems myself and to express my point of view and suggestions and they have treated with justice and equality>

\section{Axis II: Functionality}

1-There is a capacity for adaptive workers when emergencies occur at work

2-There is a commitment and adherence to the labor laws and regulations of the employees and responsibility for the daily workload of the work

Employees are keen to carry out work according to plans and programs-3

4-The Department provides appropriate training for staff to enable them to perform well

5- The management's commitment to quality performance helps to improve employee performance

6- Employees have the ability to innovate, innovate and develop work to do business correctly without discrimination. Employees have the ability to correct errors resulting from their performance. 7 -

8 - Direct supervision and continuous follow-up by presidents leads to improved employee performance and adherence to formal working hours.

Company employees have the desire and enthusiasm to do the job.9 -

-Employees have full knowledge of the job requirements they perform. 10 